\title{
Dental age estimation in Somali children and sub-adults combining permanent teeth and third molar development
}

\author{
Mari Metsäniitty ${ }^{1}(\mathbb{D}) \cdot$ Janna Waltimo-Sirén ${ }^{2} \cdot$ Helena Ranta $^{3} \cdot$ Steffen Fieuws $^{4} \cdot$ Patrick Thevissen $^{5}$
}

Received: 14 January 2019 / Accepted: 22 March 2019 / Published online: 16 April 2019

(C) The Author(s) 2019

\begin{abstract}
Estimation of an individual's age has important applications in forensics. In young individuals, it often relies on separate evaluations of permanent teeth (PT) and third molars (TM) development. Here, we analysed the age prediction performance of combined information from PT and TM in an unusual sample of healthy Somalis, born and living in Finland. PT development was staged according to Demirjian et al. (Hum Biol, 1973) and TM development according to Köhler et al. (Ann Anat, 1994), using panoramic radiographs from 803 subjects (397 males, 406 females) aged 3-23 years. A sex-specific Bayesian ageestimation model for the multivariate distribution of the stages conditional on age was fitted on PT, TM and PT and TM combined. The age-estimation performances were validated and quantified. The approach combining PT and TM only overestimated age with an ME of -0.031 years in males and -0.011 years in females, indicating the best age prediction performance.
\end{abstract}

Keywords Forensic odontology · Forensic age estimation · Age determination · Dental development · Somali · Bayesian age estimation

\section{Introduction}

Forensic age assessment among the living is mainly needed in cases where the real age of unaccompanied asylum seekers is unknown, or in criminal proceedings [1] and sometimes competitive sports [2]. In 2017, 68.5 million people had to forcibly

Mari Metsäniitty

mari.metsaniitty@helsinki.fi

1 Department of Forensic Medicine, University of Helsinki and National Institute for Health and Welfare, Kytösuontie 11, 00300 Helsinki, Finland

2 Department of Oral and Maxillofacial Diseases, University of Helsinki and Helsinki University Hospital, Kytösuontie 9, 00014 Helsinki, Finland

3 Department of Forensic Medicine, University of Helsinki, Kytösuontie 11, 00300 Helsinki, Finland

4 Leuven Biostatistics and Statistical Bioinformatics Centre (L-BioStat), University of Leuven, Kapucijnenvoer 35, 3000 Leuven, Belgium

5 Department of Imaging \& Pathology, Forensic Odontology, KU Leuven Campus Saint Raphael 7, Block A, box 7001, 3000 Leuven, Belgium leave their homes due to wars, violence and persecution [3] and in EU countries, of all minor asylum applicants $13 \%$ were unaccompanied [4]. In the future, a continuous need for forensic age estimation of unaccompanied minors with doubted age documentation is expected worldwide [5]. In forensic age assessment, dental development evaluation is a principal and widely used tool $[6,7]$. Previous studies have demonstrated significant correlations between consecutive stages of dental development and chronological age [8-21].

Improved age-estimation results are obtained by combining diverse age predictors - frequently, dental and skeletal parameters [1, 22-26]. Moreover, in children and sub-adults, permanent teeth (PT) and third molars (TM) development have been used as combined predictors [27-30]. Analyses of models for PT, TM, and combined PT + TM have been tested on United Arab Emirati [27], Brazilian [28], Japanese [29], and Malaysian children [30], but to our knowledge not in populations of Black African origin.

The wide prediction intervals in age estimations based on third molar development are problematic (mean width of $95 \%$ prediction intervals approximately 6 years) $[9,31,32]$. Recent scientific evidence shows that ethnic differences are minimal in age estimations based on tooth development [11, 33, 34]. Therefore, when using third molars for age estimation, in 
absence of population-specific data, reference data with an age range covering the whole developmental track and a uniform age distribution are recommended rather than a populationspecific reference sample $[8,11,32,35]$. A benefit of the Bayesian approach is that it does not show a tendency of attraction to the middle (overestimating the young, underestimating the old), as is the case in regression models [9, 36-39].

In the literature, controversies still exist regarding possible differences in the dental development between Black and other populations [12, 40-42], although more and more evidence of equality has been appearing [11, 20, 33, 35, 43-46]. Studies on the dental development in sub-Saharan populations and in Somalis, indigenous to Northeast Africa, are few, however $[12,41,47]$. Recently, permanent tooth development has been studied in the South-African Black population [46], in Botswanan children [40], and in Somali children born in Finland [44]. Studies of third molar development in subSaharan populations were also recently published on South African [35, 43, 48-50], Sudanese [20], Kenyan [45], Botswanan [51], Nigerian and Senegalese individuals [35], and on Northeast Africans from Libya [52], Morocco [53] and Sudan [20].

The study aim was to analyse the age prediction performance of permanent teeth and third molar development, separately and combined, using a Bayesian approach, to detect if and in what age-groups added tooth information improves the accuracy of age prediction. These were analysed using a unique material-Somali children and subadults, born and living in Finland, with reliable data on chronological age and general health.

\section{Materials and methods}

The Research Ethics Committee of the Hjelt Institute, University of Helsinki, Finland granted ethical approval (no. 02/2010), and the division of Oral Health Care of the Department of Social Services and Health Care in Helsinki, Finland provided the research permit (\#HEL 2015-010918). All individuals included were born in Finland after 1.1.1980, had permanent residence in Helsinki, spoke Somali as their native language and both of their parents were born in Somalia. A search for individuals fitting the criteria was performed by the Finnish Population Register Centre, and 2115 individuals were discovered. From 811 of those individuals, 1231dental panoramic radiographs taken for dental care purposes were found in the division of Oral Health Care at the Department of Social Services and Health Care in Helsinki. Medical abnormalities, possibly affecting dental development, were an exclusion criterion. Only one dental panoramic radiograph per eligible individual was selected, aiming at a homogenous age distribution. The final studied material included dental panoramic radiographs from 803 subjects ( 397 males, 406 females) in the age range from 3 to 23 years (Table 1).

The development of the seven left mandibular permanent teeth (PT; World Dental Federation (FDI) 31 to 37) was staged according to Demirjian et al. [19]. The technique is universally applied to permanent teeth $[34,54]$. When one or more index teeth were missing, the contra-lateral homologous teeth were staged. The development of all present third molars (TM) were staged according to the 10-point staging technique developed by Gleiser and Hunt [55] and modified by Köhler et al. [21]. Köhler staging has been shown to be most suitable for age predictions in the late developmental stages of third molars [10]. Inter- and intra-observer reliability was tested, intra-observer reliability by re-examining 37 dental panoramic radiographs after 2 months. The agreements were quantified using Kappa and weighted Kappa statistics.

Three approaches were applied: using only the PT, using only the TM and using both PT and TM. The analyses were performed on a dataset with all subjects having at least four of the seven permanent index teeth and at least one third molar. For all three approaches, PT, TM and PT + TM, a Bayesian age-estimation model for the multivariate distribution of the stages conditional on age (multivariate continuation ratio model) was fitted as described in Boldsen et al. [56] and Fieuws et al. [57]. The probability density function using

Table 1 Age and sex distribution of the Somali sample

\begin{tabular}{lrrrrrr}
\hline Age (years) & Males & Percent & Females & Percent & Total & Percent \\
\hline $3-3.99$ & 1 & 0.25 & 0 & 0.00 & 1 & 0.12 \\
$4-4.99$ & 3 & 0.76 & 1 & 0.25 & 4 & 0.50 \\
$5-5.99$ & 8 & 2.02 & 6 & 1.48 & 14 & 1.74 \\
$6-6.99$ & 19 & 4.79 & 20 & 4.93 & 39 & 4.86 \\
$7-7.99$ & 37 & 9.32 & 47 & 11.58 & 84 & 10.46 \\
$8-8.99$ & 48 & 12.09 & 50 & 12.32 & 98 & 12.20 \\
$9-9.99$ & 51 & 12.85 & 50 & 12.32 & 101 & 12.58 \\
$10-10.99$ & 49 & 12.34 & 36 & 8.87 & 85 & 10.59 \\
$11-11.99$ & 43 & 10.83 & 36 & 8.87 & 79 & 9.84 \\
$12-12.99$ & 38 & 9.57 & 27 & 6.65 & 65 & 8.09 \\
$13-13.99$ & 27 & 6.80 & 31 & 7.64 & 58 & 7.22 \\
$14-14.99$ & 17 & 4.28 & 20 & 4.93 & 37 & 4.61 \\
$15-15.99$ & 17 & 4.28 & 22 & 5.42 & 39 & 4.86 \\
$16-16.99$ & 17 & 4.28 & 17 & 4.19 & 34 & 4.23 \\
$17-17.99$ & 8 & 2.02 & 11 & 2.71 & 19 & 2.37 \\
$18-18.99$ & 7 & 1.76 & 14 & 3.45 & 21 & 2.62 \\
$19-19.99$ & 0 & 0.00 & 8 & 1.97 & 8 & 1.00 \\
$20-20.99$ & 3 & 0.76 & 7 & 1.72 & 10 & 1.25 \\
$21-21.99$ & 2 & 0.50 & 3 & 0.74 & 5 & 0.62 \\
$22-22.99$ & 1 & 0.25 & 0 & 0.00 & 1 & 0.12 \\
$23-23.99$ & 1 & 0.25 & 0 & 0.00 & 1 & 0.12 \\
Total & 397 & 100 & 406 & 100 & 803 & 100 \\
\hline & & & & & &
\end{tabular}


Table 2 Intra- and inter-observer agreement using Kappa and weighted Kappa values and their 95\% confidence intervals
Kappa statistics

\begin{tabular}{|c|c|c|c|c|c|c|c|c|}
\hline & \multicolumn{4}{|c|}{ Intra-observer } & \multicolumn{4}{|c|}{ Inter-observer } \\
\hline & \multicolumn{2}{|l|}{ PT } & \multicolumn{2}{|l|}{ TM } & \multicolumn{2}{|l|}{ PT } & \multicolumn{2}{|l|}{$\mathrm{TM}$} \\
\hline & Value & $95 \% \mathrm{CI}$ & Value & $95 \% \mathrm{CI}$ & Value & $95 \% \mathrm{CI}$ & Value & $95 \% \mathrm{CI}$ \\
\hline Simple Kappa & 0.95 & $0.92 ; 0.98$ & 0.94 & $0.89 ; 0.99$ & 0.97 & $0.95 ; 1.00$ & 0.94 & $0.89 ; 0.99$ \\
\hline Weighted Kappa & 0.98 & $0.96 ; 0.99$ & 0.97 & $0.95 ; 0.99$ & 0.99 & $0.98 ; 1.00$ & 0.97 & $0.95 ; 0.99$ \\
\hline
\end{tabular}

PT permanent teeth 31-37, TM third molars, 95\% CI 95\% confidence interval
Bayes theorem was applied where the posterior distribution of age presents the prediction intervals which were presented as estimated likelihood curves. Point estimates for age were the maximum likelihood estimates. In the forensic age estimation, prior distribution could be constructed from previous information of the ages of dental developmental stages. In particular, transition analysis with ordinal data referring to an estimation procedure, where the direction of sequence of development is fixed and inferences about one stage to the next can be made, was used. The continuation ratio model for ordinal data models the probability of one particular category given the categories preceding it. The benefit of the method is that the approach is applicable for multiple age indicators. Therefore, the product of univariate likelihoods is used, and the resulting too small prediction intervals were corrected by the ad hoc procedure described by Boldsen et al. [56]. Three models were established for males and females separately and validated using 10 -fold cross-validation. The sample was partitioned in ten subsets. The analysis was performed on one subset (training subset) and validated on the remaining subset (validation subset). This procedure was repeated on each subset and related remaining subset, and the obtained results $(n=10)$ were averaged [58]. The age-estimation performances were quantified by calculating the mean error (ME; true age minus predicted age), the mean absolute error (MAE) and root mean squared error (RMSE). The coverage of the obtained 95\% prediction intervals was tested. Results were calculated over the total age range and in 1-year age intervals.

The described approach was implemented with SAS software (version 9.4 of the SAS system for Windows, SAS Institute Inc., Cary, NC, USA) using PROC NLMIXED to fit the continuation-ratio models and to evaluate the conditional likelihoods.

\section{Results}

The intra- and inter-observer Kappa and weighted Kappa values revealed an excellent level of agreement for both PT and TM staging (Table 2).
The overall age prediction performance results are presented in Table 3. On average, the combined approach $(\mathrm{PT}+\mathrm{TM})$ performed best, overestimating age by only 0.031 years (11.3 days) in males and 0.011 years (4.0 days) in females. Between approaches, all differences in ME, MAE and RMSE were significant $(p<0.0001$ for ME and $p<0.05$ for MAE and RMSE).

Considering the performances per age category of 1 year, with the approach combining PT $+\mathrm{TM}$, the ME was small and constant in the age groups from 4 to 15 years in males $(-0.222$ to 0.332 years) and from 7 to 16 years in females ( -0.327 to 0.294 years). In the PT approach, a large negative $\mathrm{ME}$ was observed in the age range from 15 to 17 years in males ( -1.791 to -1.557 years) and in the 16 -year age category in females ( -2.133 years), as well as a sudden drop in MAE and RMSE in the 18-year age category in both sexes. In the TM approach, the ME values had moderate variation in the age categories from 9 to

Table 3 Average sex-specific age-prediction performances of linear continuation ratio models using permanent teeth, third molars, and the permanent teeth and third molars combined

\begin{tabular}{llll}
\hline & & Sex & \\
\cline { 3 - 4 } & & Male & Female \\
\hline Model & Value & $N=397$ & $N=406$ \\
PT & ME & -0.260 & -0.291 \\
& MAE & 1.025 & 1.110 \\
TM & RMSE & 1.391 & 1.499 \\
& ME & 0.290 & 0.298 \\
& MAE & 1.390 & 1.301 \\
PT TM & RMSE & 1.787 & 1.735 \\
& ME & -0.031 & -0.011 \\
& MAE & 0.852 & 0.909 \\
& RMSE & 1.095 & 1.175 \\
\hline
\end{tabular}

All reported values are expressed in years

$N$ number of subjects, $P T$ Permanent teeth 31-37, TM Third molars, $M E$ mean error, MAE mean absolute error, RMSE root mean square error 
21 years in males ( -0.486 to 0.794 years), whereas in females, more variation was present $(-0.406$ to 1.606 years) in respective age categories (Fig. 1).

For TM and PT + TM, the overall coverage of the $95 \%$ prediction interval fell within $1 \%$ of the interval in males and females (males $94.21 \%$ for TM and $94.96 \%$ for PT + $\mathrm{TM}$; females $95.32 \%$ for TM and $94.58 \%$ for PT + TM). For PT, the overall coverage of the $95 \%$ prediction interval was $92.95 \%$ in males and $92.86 \%$ in females.

The width in years of the $95 \%$ prediction intervals was most optimal in the 1-year age categories from 12 to 16 years for PT + TM in both males and females. Furthermore, the width in years of the $95 \%$ prediction intervals was larger in the 1-year age categories up to the age of 14 years for TM and was largest in the 1-year age categories above 14 years for PT (Fig. 2).

\section{Discussion}

The first study hypothesis was that in a Somali sample the age prediction performances will improve by combining data of permanent teeth (PT) and third molars (TM) development. The hypothesis was not rejected - the PT + TM approach compared to PM and TM alone performed the best, overestimating age by only a mean of 11.3 days in males (equal to an ME of 0.031 years) and a mean of 4.0 days in females (equal to an $\mathrm{ME}$
Males ME
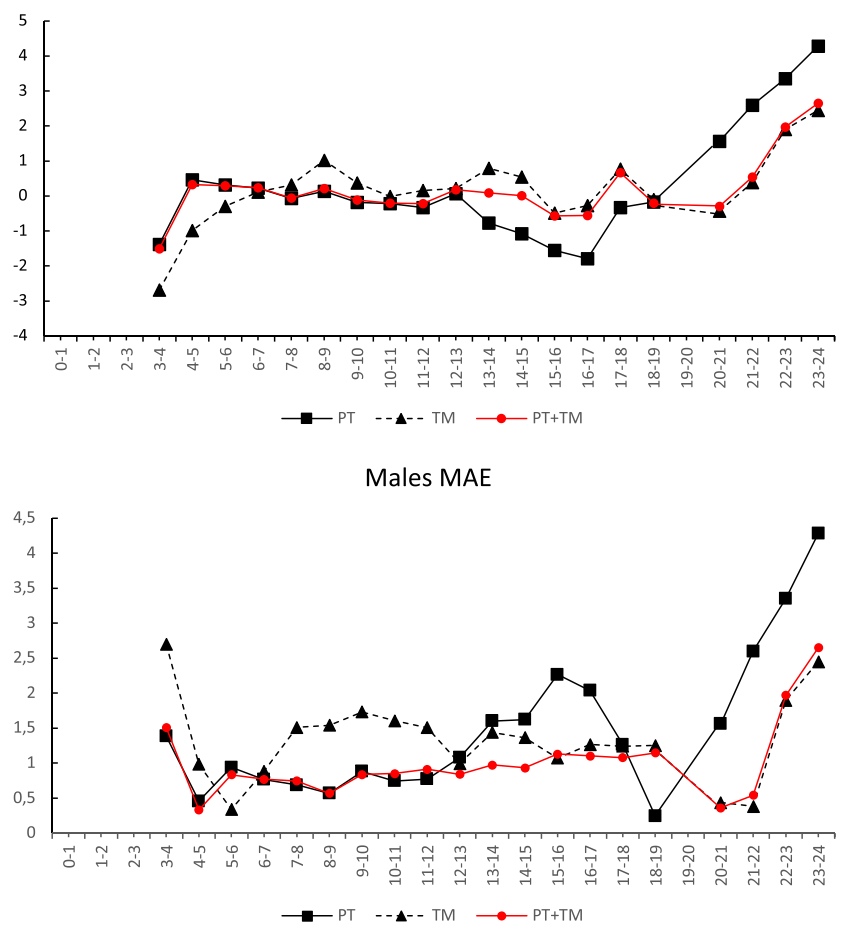

Males RMSE

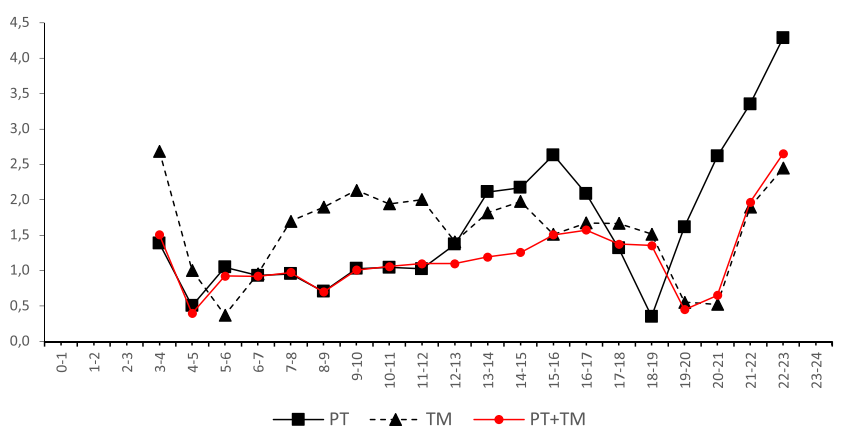

Females ME

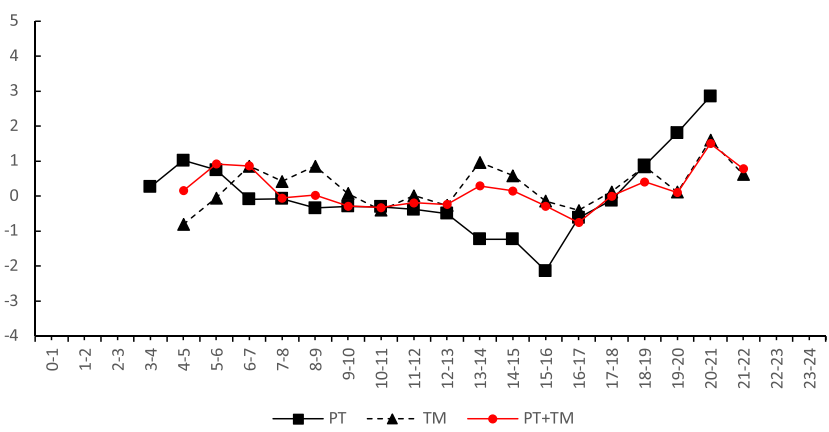

Females MAE

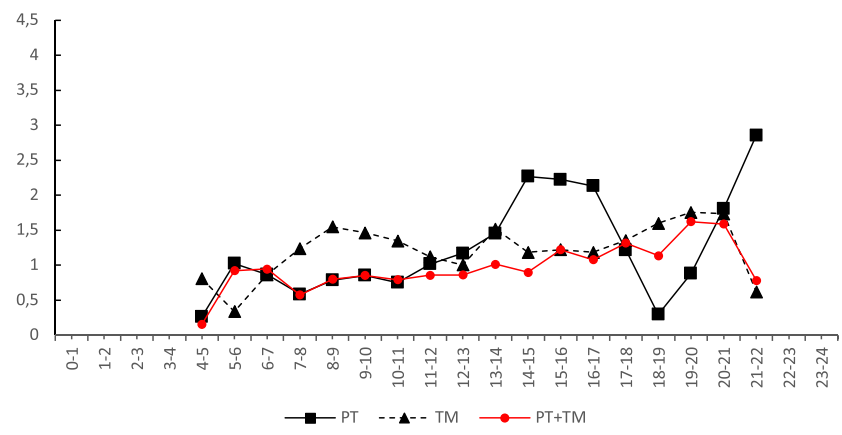

Females RMSE

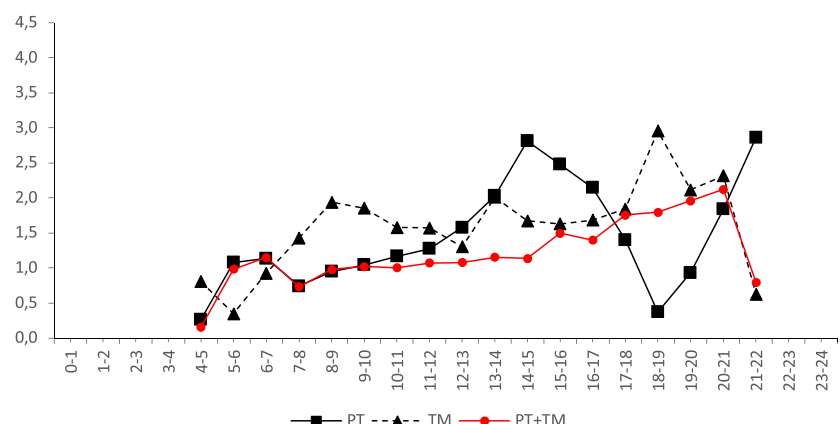

Fig. 1 Sex-specific dependence of mean error (ME) (true age minus predicted age), mean absolute error (MAE), and root mean squared error (RMSE) on age. All reported values are expressed in years. PT Permanent teeth 31-37, TM Third molars, PT + TM permanent teeth and third molars combined 
Fig. 2 Mean width in years of the 95\% prediction interval in males and females in permanent teeth, third molars, and permanent teeth, and third molars combined
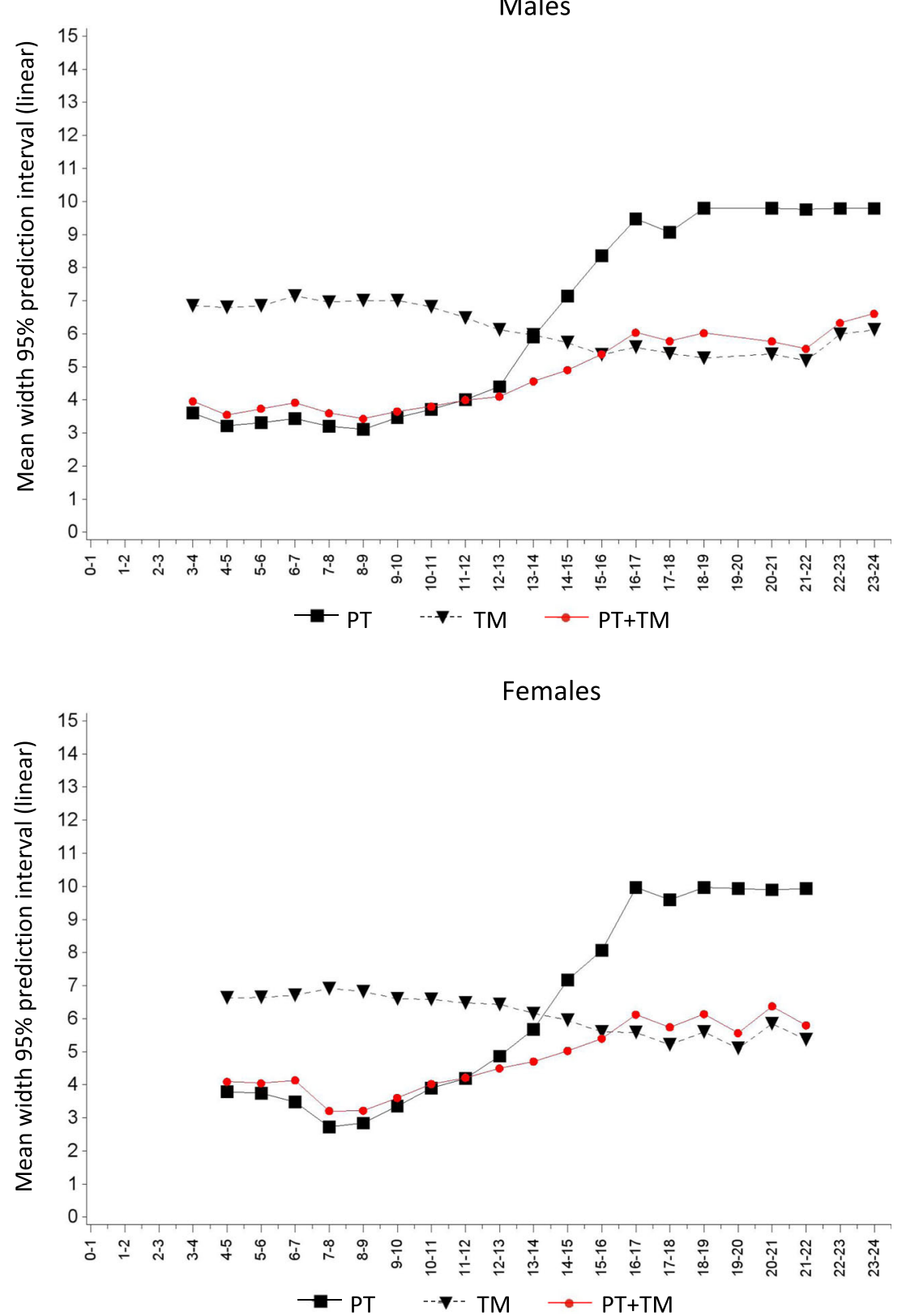

of -0.011 years). This approach also yielded the lowest magnitude and variability of error (MAE and RMSE; Table 3 ). The $\mathrm{ME}$ provides information about the direction of the error, whether the model over- or underestimates the age of an individual. The MAE quantifies the magnitude of the error and RMSE the variability in error, assigning the most weight to the largest errors. In this sample, use of only third molars for age estimation led to the biggest error and variability.

When only using PT, the sudden drops in MAE and RMSE in the age categories 18 and 19 years are explained by the point estimate for subjects with fully developed permanent teeth, which equals 18.74 years for males and 18.63 years for females but is also due to a quite small number of individuals older than 17 years in the present Somali sample. The large negative error in the age range of 15 to 17 years in males and 16 to 17 years in females is due to the majority of subjects in this category having all their permanent teeth fully developed, third molars excluded, and hence receiving a maximum age prediction.

The second study hypothesis was that dental age predictions in a Somali population behave similarly to comparable age predictions in other studied populations. An abundant number of age estimation outcomes in Black populations have been reported and discussed in the literature [12, 20, $33,35,40,41,43-46,48-50,59-63]$, but they are not comparable with the present study due to differences in study set- 
ups, sampling, variation in age distribution, teeth considered, age predictors used and staging techniques and age estimation methods applied. Models combining PT + TM have been validated in United Arab Emirati, Brazilian, Japanese and Malaysian children and sub-adults [27-30]. In these studies, the RMSE was reported because it quantifies the variance in errors, assigning large errors more weight. In Brazilian children, the $\mathrm{PT}+\mathrm{TM}$ approach resulted in RMSE values very similar to PT alone. Slightly more accurate age prediction when using the combined approach was achieved in females aged 14-15.99 years with a decrease in RMSE of 0.22 years [28]. Additionally, in Malaysian children, in the age categories between 14 and 16 years, the difference in RMSE decreased by 0.60 years in males and 0.34 years in females in the combined model $(\mathrm{PT}+\mathrm{TM})$ when compared to the PT model [30]. A similar trend was detected in the present study. The RMSE values were smaller in the PT + TM approach than in PT alone in the age categories 12-16 years in males and 10-16 years in females (Fig. 1). The reported RMSE using the four third molars (TM) alone has varied from 1.60 in females to 2.16 in males in studied United Arab Emirati [27], Japanese [29] and Malaysian [30] children and sub-adults, very similar to the present study with RMSEs of 1.735 in females and 1.787 in males. In the compared groups, TM provided the least accurate age prediction performances. Comparison of the present data with previous studies from other populations indicates that the second hypothesis was also correct; the three different age prediction approaches studied here perform equally in different ethnic groups. Thus far, the Malaysian children, in whom the average RMSE values were higher when using the combined model than the model for permanent teeth only comprise the only exception [30]. In general, the combined approach has indicated its applicability regardless of place of birth or place of residence.

The performance of PT + TM combined is optimal between 13 to 14 years of age in males and 12 to 14 years in females (Fig. 1), most likely because both PT and TM are developing at these ages. According to the literature, the age at completed permanent teeth development (up to the second molars) is, on average, 16 years $[19,64]$. The present Somali data is in agreement with that of the 16-year-olds, $80.7 \%$ of males and $96.4 \%$ of females had all mature PT. Since all PT can be mature at the earliest around 12-13 years (here, the minimum in males was 13.39 years and in females 12.89 years), the use of the PT + TM approach beginning from the age of 12 years is likely to be beneficial compared to the PT approach. Indeed, the combined PT + TM approach indicated its superiority here regarding the 95\% coverage results in the age categories from 12 to 16 years in both sexes (Fig. 2). Consequently, in forensic age estimation practice, the most benefit of combining PT and TM information will be obtained in 12 - to 15 -year-olds. In practice, development of a reference database and software for the utilisation of both permanent teeth and third molars data for increased accuracy of age estimation in this age group would be valuable. A method applying combined information from a large database of third molars and skeletal development, BioAlder, is already in use in Norway [65]. The oldest ages for immature PT were 17.37 years in males and 17.97 in females. After the age of 17 years in males and 19 years in females, the TM model performs equally well to the combined model (Fig. 1).

A previous study of the same Somali sample [44], comparing Willems model using Belgian Caucasian population [58] and the constructed Somali model, provided support for the universal application of the Willems model for forensic age estimation, since only small differences in age prediction performances were detected between the two models.

Limitations of the study were the relatively small size and uneven age distribution of the sample. Since the dental panoramic radiographs were retrospectively selected from collections taken for dental care, a limited number of radiographs were available in the youngest age groups. Individuals older than 17 years were also few, because only Somalis born in Finland were eligible. The subjective assessment of the crown or root lengths in the Köhler staging [21] might be problematic for some stages. For instance, in crown half mineralised $(\mathrm{Cr} 1 / 2)$ and crown 3/4 mineralised (Cr3/4), individual variation in crown height and root length must be taken into account. However, in the present study, this was not reflected in the performed reliability tests. Since the study was performed in Finland with living conditions different from Somalia, socio-economic factors like nutrition may have affected the outcome. Previous studies have reported advanced dental development in overweight or obese children [66, 67], whereas Elamin and Liversidge [68] found no significant difference in dental development between malnourished and normal BMI groups of young Arabs in Sudan. The main strength of our study was its setting, offering the possibility to gather reliable data on individuals of ascertained ethnic background, general health and chronological age, which may not necessarily apply to studies performed locally.

In conclusion, the age prediction performance in Somali children, born and living in Finland, improves by combining the information of PT and TM, especially in the age groups of 12 to 15 years, when both PT and TM are still developing.

Acknowledgements The authors are grateful to Senior Dental Officer Marja Noponen, DDS, PhD, and the personnel in the Unit for Specialised Oral Care in the Metropolitan Area and Kirkkonummi for arranging facilities for the study of radiographs and patient files. We thank Tuomo Maisala, DDS in Oral Health Care, Helsinki, Finland for the search of the sample.

Funding Open access funding provided by National Institute for Health and Welfare (THL). The Department of Oral and Maxillofacial Diseases, University of Helsinki, Finland funded the search of the sample from the Finnish Population Register Centre. The study was supported by a grant 
from the Finnish Women Dentists' Association, the Finnish Dental Society Apollonia, and the Minerva Foundation.

\section{Compliance with ethical standards}

Ethical approval Ethical approval was granted by the Research Ethics Committee of the Hjelt Institute, University of Helsinki (number 02/ 2010).

Conflicts of interest The authors declare that they have no conflict of interest.

Open Access This article is distributed under the terms of the Creative Commons Attribution 4.0 International License (http:// creativecommons.org/licenses/by/4.0/), which permits unrestricted use, distribution, and reproduction in any medium, provided you give appropriate credit to the original author(s) and the source, provide a link to the Creative Commons license, and indicate if changes were made.

\section{References}

1. Schmeling A, Dettmeyer R, Rudolf E, Vieth V, Geserick G (2016) Forensic age estimation: methods, certainty, and the law. Dtsche Arztebl 113:44-50. https://doi.org/10.3238/arztebl.2016.0044

2. Timme M, Steinacker J, Schmeling A (2017) Age estimation in competitive sports. Int J Legal Med 131:225-233. https://doi.org/ 10.1007/s00414-016-1456-7

3. UNHCR, the UN Refugee Agency. Figures at Glance. http://www. unhcr.org/figures-at-a-glance.html. Accessed 13 December 2018

4. Eurostat. Asylum Statistics. https://www.easo.europa.eu/sites/ default/files/Annual-Report-2017-Final.pdf. Accessed 13 December 2018

5. Pelowski M, Wamai R, Wangombe J, Nyakundi H, Oduwo G, Ngugi B, Ogembo J (2016) How would children register their own births? Insights from a survey of students regarding birth registration knowledge and policy suggestions in Kenya. PLoS One 11:e149925. https://doi.org/10.1371/journal.pone.0149925

6. European Asylum Support Office (EASO). (2014) Age assessment practice in Europe. Publications Office of the European Union. https://www.easo.europa.eu/sites/default/files/public/ EASO-Age-assessment-practice-in-Europe.pdf Accessed 13 December 2018

7. European Asylum Support Office (EASO). (2018) Practical Guide on age assessment, Second edition. doi:https://doi.org/10.2847/ 292263. https://www.easo.europa.eu/sites/default/files/easopractical-guide-on-age-assesment-v3-2018.pdf Accessed 13 December 2018

8. Thevissen P, Fieuws S, Willems G (2010) Human third molar s development: comparison of 9 country spesific populations. Forensic Sci Int 201:102-105. https://doi.org/10.1016/j.forsciint. 2010.04.054

9. Thevissen P, Fieuws S, Willems G (2010) Human dental age estimation using third molar developmental stages: does a Bayesian approach outperform regression models to discriminate between juveniles and adults? Int J Legal Med 124:35-42. https://doi.org/ 10.1007/s00414-009-0329-8

10. Thevissen P (2013) Dental age estimation in sub-adults: striving for an optimal approach. University of Leuven, Dissertation

11. Thevissen P, Alqerban A, Asaumi J, Kahveci F, Kaur J, Kim Y, Pittayapat P, Van Vlierberghe M, Zhang Y, Fieuws S, Willems G (2010) Human dental age estimation using third molar developmental stages: accuracy of age predictions not using country specific information. Forensic Sci Int 201:106-111. https://doi. org/10.1016/j.forsciint.2010.04.040

12. Olze A, van Niekerk P, Schmidt S, Wernecke K-D, Rösing F, Geserick G, Schmeling A (2006) Studies on the progress of thirdmolar mineralisation in a Black African population. HOMO 57: 209-217

13. Olze A, van Niekerk P, Ishikawa T, Zhu B, Schulz R, Maeda H, Schmeling A (2007) Comparative study on the effect of ethnicity on wisdom tooth eruption. Int J Legal Med 121: 445-448

14. AlQahtani S, Hector M, Liversidge H (2014) Accuracy of dental age estimation charts: Schour and Massler, Ubelaker and the London Atlas. American J Phys Anthropol 154:70-78. https://doi. org/10.1002/ajpa.22473

15. Arge S, Boldsen J, Wenzel A, Holmstrup P, Jensen N, Lynnerup N (2018) Third molar development in a contemporary Danish 13-25 year old population. Forensic Sci Int 289:12-17. https://doi.org/10. 1016/j.forsciint.2018.05.005

16. Baylis S, Bassed R (2017) Precision and accuracy of commonly used dental age estimation charts for the New Zealand population. Forensic Sci Int 277:223-228. https://doi.org/10.1016/j.forsciint. 2017.06.011

17. Birchler F, Kiliaridis S, Combescure C, Julku J, Pirttiniemi P, Vazquez L (2019) Dental age assessment on panoramic radiographs: comparison between two generations of young Finnish subjects. J Int Med Res 47:311-324. https://doi.org/10.1177/ 0300060518801437

18. Chaillet N, Nyström M, Demirjian A (2005) Comparison of dental maturity in children of different ethnic origins: international maturity curves for clinicians. J Forensic Sci 50:1164-1174

19. Demirjian A, Goldstein H, Tanner J (1973) A new system of dental age assessment. Hum Biol 45:211-227

20. Elamin F, Hector M, Liversidge $H$ (2017) The timing of mandibular tooth formation in two African groups. Ann Hum Biol 44:261-272. https://doi.org/10.1080/03014460.2016.1213313

21. Köhler S, Schmelzle R, Loitz C, Püschel K (1994) Die Entwicklung des Weisheitszahnes als Kriterium der Lebenaltersbestimmung. Ann Anat 176:339-345

22. Kumagai A, Willems G, Franco A, Thevissen P (2018) Age estimation combining radiographic information of two dental and four skeletal predictors in children and subadults. Int $\mathrm{J}$ Legal Med 132:1769-1777. https://doi.org/10.1007/s00414018-1910-9

23. Schumacher G, Schmeling A, Rudolf E (2018) Medical age assessment of juvenile migrants - an analysis of age marker-based assessment criteria. Publications Office of the European Union, Luxembourg. https://doi.org/10.2760/47096 Accessed 13 December 2018

24. Department of Forensic Medicine, Division of Laboratory Medicine, Oslo University Hospital. BioAlder: A tool for using biological tests to assess the age of unaccompanied minor asylum-seekers. https://oslo-universitetssykehus.no/seksjon/nyheter/ Documents/BioAlderManual_v1.0English.pdf. Accessed 13 December 2018

25. Gelbrich B, Frerking C, Weiss S, Schwerdt S, StellzigEisenhauer A, Tausche E, Gelbrich G (2015) Combining wrist age and third molars in forensic age estimation: how to calculate the joint age estimate and its error rate in age diagnostics. Ann Hum Biol 42:389-396. https://doi.org/10.3109/03014460. 2015

26. Thevissen P, Kaur J, Willems G (2012) Human age estimation combining third molar and skeletal development. Int $\mathrm{J}$ Legal Med 126:285-292. https://doi.org/10.1007/s00414-0110639-5 
27. Altalie S, Thevissen P, Fieuws S, Willems G (2014) Optimal dental age estimation practice in United Arab Emirates' children. J Forensic Sci 59:383-385. https://doi.org/10.1111/1556-4029. 12351

28. Franco A, Thevissen P, Fieuws S, Souza P, Willems G (2013) Applicability of Willems model for dental age estimations in Brazilian children. Forensic Sci Int 231:401.e1-401.e4. https:// doi.org/10.1016/j.forsciint.2013.05.030

29. Ramanan N, Thevissen P, Fieuws S, Willems G (2012) Dental age estimation in Japanese individuals combining permanent teeth and third molars. J Forensic Odontostomatol 30:34-39

30. Yusof M, Thevissen P, Fieuws S, Willems G (2014) Dental age estimation in Malay children based on all permanent teeth types. Int J Legal Med 128:329-333. https://doi.org/10.1007/s00414-0130825-8

31. Liversidge $\mathrm{H}$, Marsden $\mathrm{P}$ (2010) Estimating age and the likelihood of having attained 18 years of age using mandibular third molars. Br Dent J 209:E13. https://doi.org/10.1038/sj.bdj.2010.976

32. Tangmose S, Thevissen P, Lynnerup N, Willems G, Boldsen J (2015) Age estimation in the living: transition analysis on developing third molars. Forensic Sci Int 257:512.e1-512.e7. https://doi. org/10.1016/j.forsciint.2015.07.049

33. Liversidge H, Smith B, Maber M (2010) Bias and accuracy of age estimation using developing teeth in 946 children. Am J Phys Anthropol 143:545-554

34. Maber M, Liversidge H, Hector M (2006) Accuracy of age estimation of radiographic methods using developing teeth. Forensic Sci Int 159(Suppl):S68-S73

35. Liversidge H, Peariasamy K, Folayan M, Adeniyi A, Ngom P, Mikami Y, Shimada Y, Kuroe K, Tvete IF, Kvaal SI (2017) A radiographic study of the mandibular third molar root development in different ethnic groups. J Forensic Odontostomatol 2:97-108

36. Sironi E, Taroni F, Baldinotti C, Nardi C, Norelli G, Gallidabino M, Pinchi V (2018) Age estimation by assessment of pulp chamber volume: a Bayesian network for the evaluation of dental evidence. Int J Legal Med 132:1125-1138. https://doi.org/10.1007/s00414017-1733-0

37. Aykroyd R, Lucy D, Pollard A, Roberts C (1999) Nasty, brutish, but not necessarily short: a reconsideration of the statistical methods used to calculate age at death from adult human skeletal and dental indicators. Am Antiq 64:55-70

38. Aykroyd RG, Lucy D, Pollard AM, Solheim T (1997) Technical note: regression analysis in adult age estimation. Am J Phys Anthropol 104:259-265

39. Lucy D, Aykroyd RG, Pollard AM (2002) Non-parametric calibration for age estimation. Appl Stat 52:185-196

40. Cavrić J, Vodanović M, Marušić A, Galić I (2016) Time of mineralization of permanent teeth in children and adolescents in Gaborone, Botswana. Ann Anat 203:24-32. https://doi.org/10. 1016/j.aanat.2015.08.001

41. Phillips V, van Wyk KT (2009) Dental age-related tables for children of various ethnic groups in South Africa. J Forensic Odontostomatol 27:29-44

42. Liversidge $\mathrm{H}$ (2008) Timing of human mandibular third molar formation. Ann Hum Biol 35:294-321. https://doi.org/10.1080/ 03014460801971445

43. Esan T, Schepartz L (2018) Accuracy of the Demirjian and Willems methods of age estimation in a Black Southern African population. Leg Med (Tokyo) 31:82-89. https://doi.org/10.1016/j.legalmed. 2018.01.004

44. Metsäniitty M, Waltimo-Sirén J, Ranta H, Fieuws S, Thevissen P (2018) Dental age estimation in Somali children using the Willems et al. model. Int J Legal Med 32:1779-1786. https://doi.org/10. 1007/s00414-018-1926-1
45. Kihara N, Gichangi P, Liversidge H, Butt F, Gikenye G (2017) Dental age estimation in a group of Kenyan children using Willems' method: a radiographic study. Ann Hum Biol 44:614 621. https://doi.org/10.1080/03014460.2017.1371794

46. Willems G, Lee S-S, Uys A, Bernitz H, Cadenas de Llano-Pérula M, Fieuws S, Thevissen P (2018) Age estimation based on Willems method versus new country-specific method in South African black children. Int J Legal Med 132:599-607. https://doi.org/10.1007/ s00414-017-1686-3

47. Davidson L, Rodd H (2001) Interrelationships between dental age and chronological age in Somali children. Community Dent Health 18:27-30

48. Angelakopoulos N, De Luca S, Velandia Palacio L, Coccia E, Ferrante L, Cameriere R (2018) Third molar maturity index (I3M) for assessing age of majority: study of a black South African sample. Int J Legal Med 132:1457-1464. https://doi.org/10.1007/ s00414-018-1818-4

49. Esan T, Scherpartz LA (2018) The WITS atlas: a Black Southern African dental atlas for permanent tooth formation and emergence. Am J Phys Anthropol 166:208-218. https://doi.org/10.1002/ajpa. 23424

50. Uys A, Bernitz H, Pretorius S, Steyn M (2018) Estimating age and the probability of being at least 18 years of age using third molars: a comparison between Black and White individuals living in South Africa. Int J Legal Med 132:1437-1446. https://doi.org/10.1007/ s00414-018-1877-6

51. Cavrić J, Galić I, Vodanović M, Brkić H, Gregov J, Viva S, Rey L, Cameriere R (2016) Third molar maturity index (I3M) for assessing age of majority in a black African population in Botswana. Int $\mathrm{J}$ Legal Med 130:1109-1120. https://doi.org/10.1007/s00414-0161344-1

52. Dardouri AAK, Cameriere R, De Luca S, Vanin S (2016) Third molar maturity index by measurements of open apices in a Libyan sample of living subjects. Forensic Sci Int 267:230.e1-230.e6. https://doi.org/10.1016/j.forsciint.2016.07.020

53. Garamendi PM, Landa MI, Ballesteros J, Solano MA (2005) Reliability of the methods applied to assess age minority in living subjects around 18 years old. A survey on a Moroccan origin population. Forensic Sci Int 154:3-12

54. Flood S, Franklin D, Turlach B, McGeachie J (2013) A comparison of Demirjian's four dental development methods for forensic age estimation in south Australian sub-adults. J Forensic Legal Med 20:875-883. https://doi.org/10.1016/j. jflm.2013.07.002

55. Gleiser I, Hunt E (1955) The permanent first molar: its calcification, eruption and decay. Am J Phys Anthropol 13:253-284

56. Boldsen J, Milner G, Koningsberg L, Wood J (2002) Transition analysis. A new method for estimating age from skeletons. In: Hoppa RD, Vaupel JW (eds) Paleodemography age distributions from skeletal samples. Cambridge University Press, Cambridge, pp 73-106

57. Fieuws S, Willems G, Larsen-Tangmose S, Lynnerup NB, Thevissen P (2016) Obtaining appropriate interval estimates for age when multiple indicators are used: evaluation of an ad hoc procedure. Int J Legal Med 130:489-499. https://doi.org/10.1007/ s00414-015-1200-8

58. Gong G (1986) Cross-validation, the jackknife, and the bootstrap: excess error estimation in forward logistic regression. JASA 81: 108-113. https://doi.org/10.2307/2287975

59. Blankenship J, Mincer H, Anderson K, Woods M, Burton E (2007) Third molar development in the estimation of chronologic age in American blacks as compared with whites. J Forensic Sci 52:428433

60. Harris E, McKee J (1990) Tooth mineralization standards for blacks and whites from the middle southern United States. J Forensic Sci $35: 859-872$ 
61. Ifesanya J, Adeyemi A (2012) Accuracy of age estimation using Demirjian method among Nigerian children. Afr J Med Med Sci 41: 297-300

62. Mincer H, Harris E, Berryman H (1993) The A.B.F.O. study of third molar development and its use as an estimator of chronological age. J Forensic Sci 38:379-390

63. Phillips V, van Wyk KT (2009) Testing standard methods of dental age estimation by Moorrees, fanning and Hunt and Demirjian, Goldstein and Tanner on three south African children samples. J Forensic Odontostomatol 27:20-28

64. Willems G, Van Olmen A, Spiessens B, Carels C (2001) Dental age estimation in Belgian children: Demirjian's technique revisited. J Forensic Sci 46:893-895

65. Bleka Ø, Rolseth V, Dahlberg PS, Saadé A, Saadé M, Bachs L (2018) BioAlder: a tool for assessing chronological age based on two radiological methods. Int J Legal Med doi: https://doi.org/10. 1007/s00414-018-1959-5

66. Chehab DA, Tanbonliong T, Peyser J, Udin R (2017) Association between body mass index and dental age in Hispanic children. Gen Dent 65:54-58

67. Jääsaari P, Tolvanen M, Niinikoski H, Karjalainen S (2016) Advanced dental maturity of Finnish 6- to 12-yr-old children is associated with high energy intake. Eur J Oral Sci 124:465-471

68. Elamin F, Liversidge H (2013) Malnutrition has no effect on the timing of human tooth formation. PLoS One 8:e72274

Publisher's note Springer Nature remains neutral with regard to jurisdictional claims in published maps and institutional affiliations. 